\title{
CRYSTAL SIZE AND ORIENTATION PATTERNS IN THE WISCONSIN-AGE ICE FROM DYE 3, GREENLAND
}

\author{
by
}

\author{
C.C. Langway, Jr, H. Shoji and N. Azuma
}

(Department of Geological Sciences, State University of New York at Buffalo, 4240 Ridge Lea Road, Amherst, NY 14226, U.S.A.)

\begin{abstract}
Crystal size and $c$-axis orientation patterns were measured on the Dye 3, Greenland, deep ice core in order to investigate time-dependent changes or alterations in the physical character of the core as a function of time after recovery. The physical measurements were expanded to include depth intervals not previously studied in the field. The recent study focused on core samples located between $1786 \mathrm{~m}$ and the bottom of the ice sheet at $2037 \mathrm{~m}$.

Manual $c$-axis measurements were made on 23 new thin sections using a Rigsby-type universal stage. A new semi-automatic ultrasonic wave-velocity measuring device was developed in order to compare the results with the earlier manual measurements and to study an additional 114 ice-core samples in the Wisconsin-age ice. Crystal-size measurements were made on specimen surfaces by inducing evaporation grooves at crystal boundaries and measuring linear intercepts. The ultrasonically measured test samples were subsequently cleaned and analyzed by ion chromatography in order to measure impurity concentration levels of $\mathrm{Cl}^{-}, \mathrm{NO}_{3}{ }^{-}$and $\mathrm{SO}_{4}{ }^{2-}$ and study their effects on crystal growth and $c$-axis orientation.
\end{abstract}

\section{INTRODUCTION}

To understand the dynamic processes which occur within the mass of a polar glacier it is necessary to measure the physical-property variations over the vertical profile. A continuous $2037 \mathrm{~m}$ long Greenland Ice Sheet Program (GISP) core ice was recovered at Dye 3, Greenland $\left(65^{\circ} 11^{\prime} \mathrm{N}, 43^{\circ} 49^{\prime} \mathrm{W}\right)$ between 1979 and 1981 (Gundestrup and Johnsen 1985, Langway and others 1985); it provided glacier-ice samples from the surface to bedrock of excellent quality for such an investigation. Initial multi-parameter physical measurements were made on the Dye 3 core in a field-trench laboratory immediately after each core section was augered (S.L. Herron and others 1985). Other physical-property studies were made after the ice core had been transported back to the laboratory (Shoji and Langway 1982 and 1983, S.L. Herron and Langway unpublished, Azuma unpublished).

The Holocene-Wisconsin boundary for the Dye 3, Greenland, ice core was identified at $1786 \mathrm{~m}$ depth by the stable-isotope method (Dansgaard and others 1982 and 1985) and confirmed by simultaneous sharp changes in measurements of the physical properties and an increase in wave velocity (S.L. Herron and others 1985), by a pronounced increase in $\mathrm{Cl}^{-}, \mathrm{NO}_{3}{ }^{-}$and $\mathrm{SO}_{4}{ }^{2-}$ concentration levels (M.M. Herron and Langway 1985), by a lower conductivity and a higher dust content (Hammer and others 1985), and by a higher strain-rate enhancement factor (Shoji and Langway 1985).

The laboratory studies presented here focus on core samples from the Wisconsin-age ice located between the $1786 \mathrm{~m}$ depth and the bottom of the ice sheet. Manual $c$-axis crystal-orientation measurements were made on 23 new thin sections using a Rigsby-type universal stage. A new semi-automatic crystal-orientation technique which makes use of ultrasonic wave velocities was used to measure $c$-axes on 114 other core samples. Crystal-size measurements were made on both sets of specimens. The ultrasonically measured test samples were subsequently cleaned and prepared for chemical analyses by ion chromatography in order to study the effect of impurity concentrations on the physical parameters. The results of core studies on the air bubbles, air hydrates, megascopic stratigraphy, melt layers, porosity and air permeability, micro-hardness and crystal anisotropy in the upper firn structure of the Dye 3 deep ice core will be reported elsewhere.

\section{SAMPLES AND METHODS}

Manual crystal orientations were made on the 23 thin sections, applying procedures outlined by Langway (1958), using a Rigsby-type universal stage. Crystal size was measured directly on the thin sections or from enlarged photographs. The sections were cut perpendicular to the long ice-core axis. No azimuth control was obtained.

The core samples for ultrasonic wave-velocity measurements were prepared from $3.5 \mathrm{~cm}$ thick vertical sections cut parallel to the long axis of the ice core. Each vertical rectangular block section $(8 \times 8 \times 3.5 \mathrm{~cm})$ was first cut by band saw and then smooth-finished, using a microtome blade. No azimuth control was obtained. All samples were systematically spaced at an interval of about

a.

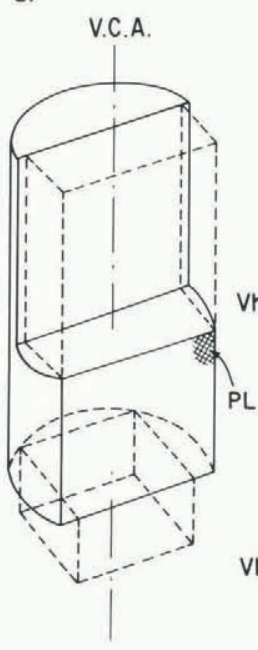

b.

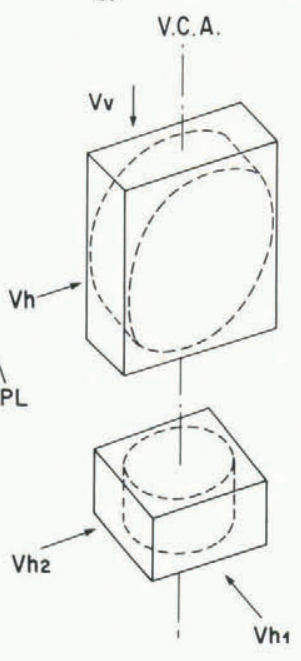

C.

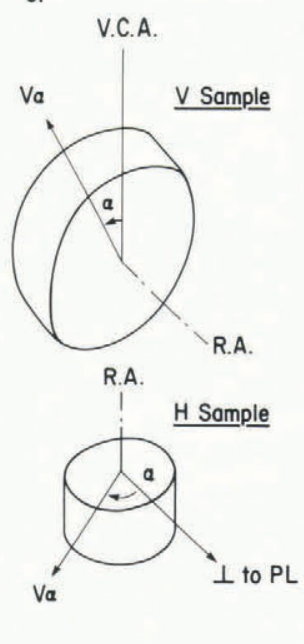

Fig.1. Sample-preparation procedures for ultrasonic wave-velocity measurements. The vertical specimen (upper figures) and horizontal specimen (lower figures) are both part of the same ice-core sample. (a) Specimens are cut parallel (PL) to the long vertical core axis (V.C.A.). (b) After ultrasonic velocity measurements, each specimen is lathed into cylinders. (c) Ultrasonic velocity is measured along the circumference of the cylinder on a rotation axis (R.A.) which is perpendicular to PL (vertical specimen) or parallel to V.C.A. (horizontal specimen). 
TABLE I. THIN-SECTION SAMPLES FROM THE WISCONSIN-AGE DYE 3 ICE CORE.

\begin{tabular}{|c|c|c|c|c|c|}
\hline $\begin{array}{c}\text { Sample } \\
\text { no. }\end{array}$ & $\begin{array}{l}\text { Depth } \\
\text { m }\end{array}$ & $\begin{array}{l}\text { Number of } \\
c \text {-axes } \\
\text { measured } \\
(\mathrm{N})\end{array}$ & $\begin{array}{l}\text { Fabric } \\
\text { statistics } \\
(\mathrm{R} / \mathrm{N})\end{array}$ & $\begin{array}{c}\text { Inclination } \\
\text { of mean } c \text {-axes } \\
\text { from core axis } \\
\text { degree }\end{array}$ & $\begin{array}{c}\text { Grain- } \\
\text { size } \\
\text { mm }\end{array}$ \\
\hline 1 & 1658.40 & 99 & 0.82 & 1 & $>10$ \\
\hline 2 & 1820.67 & 140 & 0.98 & 12 & 0.91 \\
\hline 3 & 1836.45 & 157 & 0.95 & 10 & 1.2 \\
\hline 4 & 1850.45 & 150 & 0.97 & 11 & 1.1 \\
\hline 5 & 1852.20 & 150 & 0.96 & 10 & 0.93 \\
\hline 6 & 1860.22 & 190 & 0.95 & 9 & 1.7 \\
\hline 7 & 1863.59 & 200 & 0.94 & 8 & 1.0 \\
\hline 8 & 1867.01 & 180 & 0.98 & 8 & 1.5 \\
\hline 9 & 1870.89 & 200 & 0.94 & 9 & 0.92 \\
\hline 10 & 1884.30 & 178 & 0.98 & 9 & 1.2 \\
\hline 11 & 1889.63 & 180 & 0.94 & 10 & 1.0 \\
\hline 12 & 1895.27 & 180 & 0.98 & 7 & 1.7 \\
\hline 13 & 1897.45 & 132 & 0.97 & 8 & 1.2 \\
\hline 14 & 1899.61 & 152 & 0.97 & 15 & 1.1 \\
\hline 15 & 1908.27 & 196 & 0.97 & 10 & 1.9 \\
\hline 16 & 1911.27 & 184 & 0.98 & 9 & 0.97 \\
\hline 17 & 1929.35 & 200 & 0.97 & 11 & 2.1 \\
\hline 18 & 1933.24 & 176 & 0.94 & 10 & 1.4 \\
\hline 19 & 1943.42 & 132 & 0.97 & 5 & 1.8 \\
\hline 20 & 1961.21 & 200 & 0.95 & 15 & 1.0 \\
\hline 21 & 1980.11 & 154 & 0.98 & 6 & 1.8 \\
\hline 22 & 1995.10 & 188 & 0.89 & 10 & 3.3 \\
\hline 23 & 2006.16 & 178 & 0.99 & 7 & 2.2 \\
\hline
\end{tabular}

$2.2 \mathrm{~m}$ within the depth range of 1788 and $2034 \mathrm{~m}$. Sample-preparation and orientation procedures are shown in Figure 1. Ultrasonic wave-velocity measurements were made first on the rectangular blocks in both a vertical $\left(\mathrm{V}_{\mathrm{v}}\right)$ and a horizontal $\left(V_{h}\right)$ direction. Thereafter the rectangular block was lathed into a cylindrical shape $(\mathrm{d}=7 \mathrm{~cm}, \mathrm{~h}=3.5 \mathrm{~cm})$, as shown in Figure 1. For the new analytical technique the wave velocities were measured along the circumference of the cylinders by mounting the specimen on the lathe carriage and manually rotating the cylinder in increments of $5^{\circ}$. A Krautkramer-Branson USL 38 with a $2.25 \mathrm{MHz}$ transducer was used to propagate an ultrasonic P-wave. A

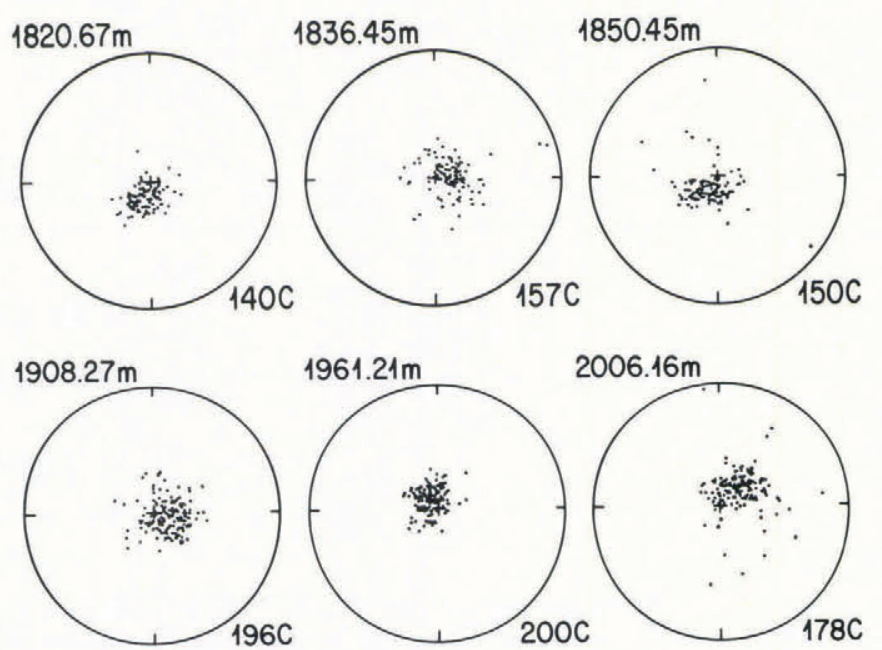

Fig.2. Fabric diagrams of six typical thin sections from Wisconsin-age ice measured on a Rigsby-type stage. The center of each diagram (lower hemisphere of Schmidt-net projection) corresponds to the vertical long-core axis. low-viscosity silicone oil was used as a coupler. Measurements were performed in a $15^{\circ} \pm 2^{\circ} \mathrm{C}$ cold-room. Crystal size was measured on these samples by thermal-etching grain-boundary grooves on the flat surface of the cylinder and measuring linear intercepts. Finally, each sample was surface-microtomed, cleaned and melted, using established clean-room procedures, and measured for $\mathrm{Cl}^{-}, \mathrm{NO}_{3}{ }^{-}$and $\mathrm{SO}_{4}{ }^{2-}$ concentration levels by ion chromatography (Langway and Goto-Azuma 1988, this volume), applying procedures previously reported (M.M. Herron and Langway 1985). Samples from the near-bottom silty ice (below $2008 \mathrm{~m}$ depth) were not chemically analyzed.

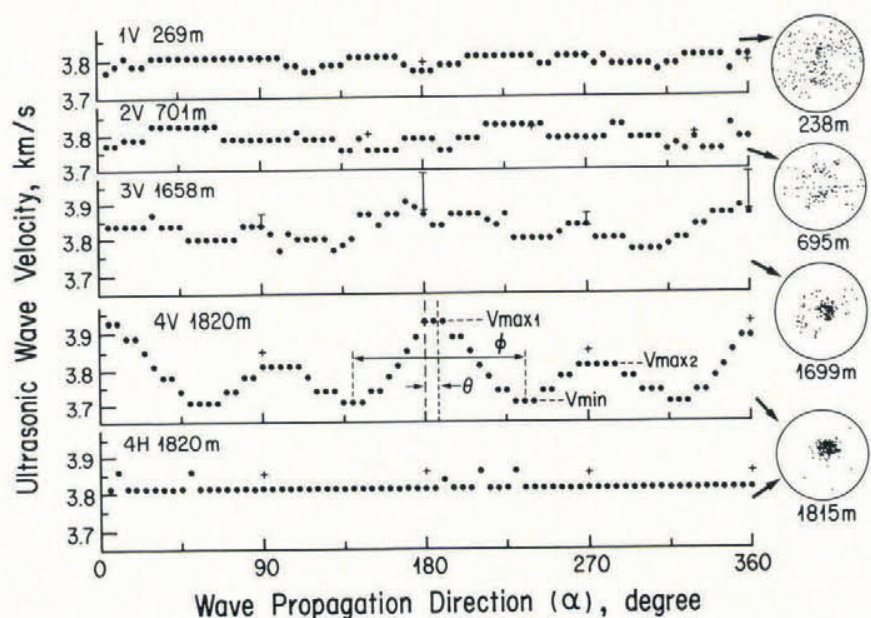

Fig.3. P-wave ultrasonic wave-velocity curves compared with four $c$-axis fabric diagrams measured on a Rigsby-type stage (S.L. Herron and others 1985). Wave propagation is plotted parallel to the vertical plane of the core for vertical specimens $(1 \mathrm{~V}, 2 \mathrm{~V}, 3 \mathrm{~V}$ and $4 \mathrm{~V})$ or perpendicular to the long-core axis for the horizontal specimen $(4 \mathrm{H})$. 


\section{RESULTS}

The results of the fabric and crystal-size measurements on the 23 manually measured sections are listed in Table I. All sections below $1786 \mathrm{~m}$ depth show strong single-maximum fabric patterns. As examples, six of the fabric diagrams are shown in Figure 2. Section depth is identified in the top left of each diagram in Figure 2 and the number of crystals measured is shown in the bottom right. The results of these measurements were compared with similar field measurements which were made by S.L. Herron and others (1985) in order to investigate possible time-dependent changes or alterations in the physical character of the ice cores. No marked differences in orientation pattern or changes in grain-size were observed either in the thin sections reported on here or in the sections measured in the field about 5 years earlier.

Previously reported studies of the crystal anisotropy in ice sheets were usually made by measuring the ultrasonic velocities on selected ice-core samples in two directions: the vertical and the horizontal (Bennett 1972, Kohnen and Langway 1977, Kohnen and Bentley 1977). For this study a new semi-automatic multi-directional technique was developed. The feasibility of the method was first tested by comparing the semi-automatic results from the 269,701 , 1658 and $1820 \mathrm{~m}$ depths with the field results of S.L. Herron and others (1985) at the 238,695, 1699 and $1815 \mathrm{~m}$ depths respectively (Fig.3). As shown in Figure 3, the ultrasonic wave-velocity curve which results from measuring sample 1V from $269 \mathrm{~m}$ is nearly constant throughout the 360 rotation and corresponds quite well to the random orientation pattern indicated in the fabric diagram of the $238 \mathrm{~m}$ section. Curve $2 \mathrm{~V}$ from $701 \mathrm{~m}$ shows slightly higher wave velocities between $30^{\circ}$ and $65^{\circ}$, which corresponds to the slightly more circular convergence of $c$-axes shown in the fabric diagram at $695 \mathrm{~m}$. The $2 \mathrm{~V}$ velocity curve is asymmetrical with reference to $\alpha=180^{\circ}$ because the $c$-axis concentration is asymmetrical. Curve $3 \mathrm{~V}$ from $1658 \mathrm{~m}$ shows the highest velocity values to be near vertical and compares favorably with the strong vertical fabric pattern displayed in the diagram from $1669 \mathrm{~m}$. Curve $4 \mathrm{~V}$ from $1820 \mathrm{~m}$ shows a pronounced and relatively smooth sinusoidal velocity curve, which is reflected as a very strong, near-vertical, single-maximum fabric pattern in the diagram from $1815 \mathrm{~m}$. Some velocity curves show a flat-velocity maximum and minimum along the wave-propagation direction due to the $\pm 8 \mathrm{~m} / \mathrm{s}$ velocity resolution limits of the apparatus. Crosses superimposed on the velocity curves in Figure 3 represent velocity measurements made on the 114 block samples in two directions before the cylinder was made and tested. The velocity differences result from the resolution limits of the apparatus and the geometry of the sample. Temperature-induced error in velocity measurements is estimated to be within $10 \mathrm{~m} / \mathrm{s}$. Curve $4 \mathrm{H}$ from the $1820 \mathrm{~m}$ specimen $(\mathrm{d}=4.5 \mathrm{~cm}, \mathrm{~h}=3.5 \mathrm{~cm})$ indicates that the wave velocity in the horizontal plane is nearly isotropic, as it should be when wave-propagation direction is constantly oriented perpendicular to a strong vertically oriented fabric pattern. The above study demonstrates the validity of the multi-directional ultrasonic wave-velocity measurements for determining $c$-axis crystal-orientation data over a complete spectrum of fabric patterns and configurations.

Since the pole of a strong single-maximum fabric pattern is coincident to the pole of the mean $c$-axis direction, additional detailed information can be obtained by considering the geometry of the $c$-axis distribution patterns. The ultrasonic velocity should be highest along the pole direction and decrease as the angle increases from the mean pole direction. The lower velocity $\left(\mathrm{V}_{\min }\right)$ directions result in a cone-shaped configuration in which the half-apex angle is approximately $50^{\circ}$ (Bennett 1972). The velocity then increases to the second highest velocity $\left(\mathrm{V}_{\max 2}\right)$ as the wave propagation direction is inclined more than $50^{\circ}$ from the pole. In this orientation, measurements are made along a direction perpendicular to the pole direction. Since the ice-crystal $c$-axis pole direction is not usually found parallel to the vertical cutting plane of the specimen (PL in Figure 1a), the apparent highest velocity $\left(\mathrm{V}_{\operatorname{max1}}\right)$ is usually measured along an inclined direction, $\theta$, from the vertical core axis in PL plane. When the pole direction rotates away from PL plane, $V_{\max 1}$ decreases, due to the increase in the inclination angle from the pole direction. With this rotation,
Ultrasonic Velocity, $\mathrm{km} / \mathrm{s}$

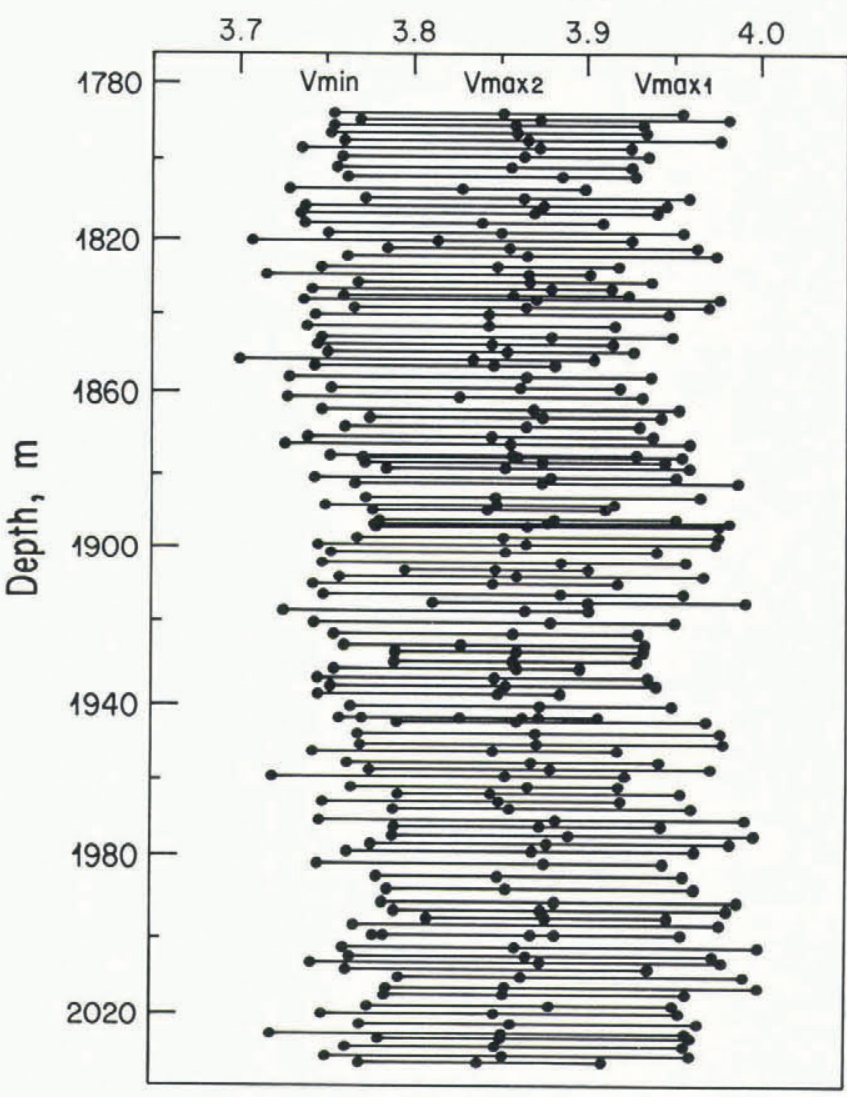

Fig.4. Ultrasonic wave velocities measured on the 114 Wisconsin-age ice specimens. The measured values of $\mathrm{V}_{\max 1}, \mathrm{~V}_{\max 2}$ and $\mathrm{V}_{\min }$ are plotted at each specimen depth. The general feature of data obtained is an approximately constant level of strong anisotropy in $c$-axis orientation distributions for the Wisconsin-age ice, including the bottom silty-ice specimens.

$\mathrm{V}_{\max 2}$ and $\mathrm{V}_{\min }$ remain the same, even though the angle distance, $\phi$, decreases between two $V_{\text {min }}$ directions with an interspersed $\mathrm{V}_{\max 1}$. Therefore, $\delta \mathrm{V}$, the velocity difference between $V_{\max 2}$ and $V_{\min }$, does not depend on rotation of the pole direction and can be used to indicate the $c$-axis concentration strength along the pole direction.

The results of the semi-automatic ultrasonic wave-velocity measurements on the 114 samples are shown in Figure 4 and listed in Table II. They indicate that a strong single-maximum fabric pattern exists for all Wisconsin-age ice, including the bottom silt-laden ice from below $2008 \mathrm{~m}$ depth. With this method it is possible to conduct $c$-axis measurements in core samples which contain embedded debris, where thin sections cannot normally be made for Rigsby-type measurements.

Ice crystal-size data for both the thin-section and ultrasonic-velocity specimens are listed in Tables I and II. Figure 5 shows crystal-size data and $\mathrm{SO}_{4}{ }^{2-}$ concentration levels plotted versus depth. Crystal size ranges from 0.5 to $3.0 \mathrm{~mm}$, with considerable variability within these limits. The main trends of the size curve show that larger-sized crystals exist from about 1790 to $1815 \mathrm{~m}$, where a sharp decrease occurs. From about 1815 to $1970 \mathrm{~m}$ there is a general and gradual increase in size. Another sharp change to increased size occurs at about $1970 \mathrm{~m}$. At $2005 \mathrm{~m}$ the curve again makes a decided shift to much smaller crystal sizes just before the near-bottom silt-laden basal ice appears at about $2008 \mathrm{~m}$. Ice crystals in the silty basal ice are the smallest of the entire profile and average less than $1 \mathrm{~mm}$. Crystal size in the deepest specimen, measured at $2034 \mathrm{~m}$, averaged $0.45 \mathrm{~mm}$. 
TABLE II. WAVE-VELOCITY SAMPLES FROM THE WISCONSIN-AGE DYE 3 ICE CORE

\begin{tabular}{|c|c|c|c|c|c|c|c|c|}
\hline $\begin{array}{c}\text { Sample } \\
\text { no. }\end{array}$ & $\begin{array}{l}\text { Sample } \\
\text { depth } \\
\text { m }\end{array}$ & $\begin{array}{l}\text { Grain- } \\
\text { size } \\
\mathrm{mm}\end{array}$ & $\begin{array}{l}V_{\max 1} \\
\mathrm{~km} / \mathrm{s}\end{array}$ & $\begin{array}{r}\mathrm{V}_{\max 2} \\
\mathrm{~km} / \mathrm{s}\end{array}$ & $\mathrm{V}_{\min } \mathrm{km/s}$ & $\begin{array}{l}\mathrm{V}(45) \\
\mathrm{km} / \mathrm{s}\end{array}$ & $\begin{array}{c}\text { Angle } \\
(\theta) \\
\text { degree }\end{array}$ & $\begin{array}{l}\text { Angle } \\
(\phi) \\
\text { degree }\end{array}$ \\
\hline 1 & 1788.24 & 2.0 & 3.955 & 3.851 & 3.754 & 3.769 & 7.5 & 98 \\
\hline 2 & 1790.18 & 0.96 & 3.982 & 3.872 & 3.769 & 3.785 & 10 & 96 \\
\hline 3 & 1791.54 & 1.1 & 3.933 & 3.858 & 3.754 & 3.754 & 5 & 95 \\
\hline 4 & 1793.43 & 1.4 & 3.935 & 3.859 & 3.752 & 3.779 & 7.5 & 96 \\
\hline 5 & 1795.43 & 1.6 & 3.977 & 3.865 & 3.760 & 3.777 & 7.5 & 103 \\
\hline 6 & 1797.43 & 1.6 & 3.926 & 3.872 & 3.736 & 3.786 & 12.5 & 103 \\
\hline 7 & 1799.43 & 1.5 & 3.936 & 3.863 & 3.759 & 3.794 & 12.5 & 96 \\
\hline 8 & 1801.94 & 1.5 & 3.926 & 3.856 & 3.756 & 3.757 & 7.5 & 96 \\
\hline 9 & 1804.42 & 1.4 & 3.929 & 3.885 & 3.762 & 3.782 & 10 & 99 \\
\hline 10 & 1807.43 & 1.6 & 3.899 & 3.828 & 3.729 & 3.752 & 5 & 103 \\
\hline 11 & 1809.43 & 1.6 & 3.959 & 3.863 & 3.772 & 3.781 & 2.5 & 95 \\
\hline 12 & 1811.44 & 1.5 & 3.946 & 3.874 & 3.738 & 3.754 & 7.5 & 99 \\
\hline 13 & 1813.44 & 1.1 & 3.941 & 3.869 & 3.735 & 3.769 & 10 & 99 \\
\hline 14 & 1815.94 & 0.90 & 3.910 & 3.839 & 3.738 & 3.744 & 7.5 & 99 \\
\hline 15 & 1818.44 & 0.68 & 3.956 & 3.850 & 3.751 & 3.767 & 2.5 & 99 \\
\hline 16 & 1820.44 & 0.80 & 3.926 & 3.814 & 3.708 & 3.726 & 2.5 & 96 \\
\hline 17 & 1822.44 & 0.91 & 3.964 & 3.855 & 3.785 & 3.785 & 5 & 101 \\
\hline 18 & 1824.44 & 0.98 & 3.975 & 3.865 & 3.762 & 3.759 & 0 & 99 \\
\hline 19 & 1827.44 & 0.82 & 3.919 & 3.848 & 3.747 & 3.747 & 2.5 & 95 \\
\hline 20 & 1829.44 & 0.81 & 3.902 & 3.866 & 3.716 & 3.724 & 2.5 & 95 \\
\hline 21 & 1831.44 & 0.85 & 3.938 & 3.867 & 3.768 & 3.768 & 12.5 & 95 \\
\hline 22 & 1833.44 & 0.90 & 3.915 & 3.879 & 3.742 & 3.739 & 2.5 & 95 \\
\hline 23 & 1835.35 & 0.80 & 3.925 & 3.857 & 3.760 & 3.759 & 5 & 95 \\
\hline 24 & 1836.35 & 0.94 & 3.977 & 3.870 & 3.737 & 3.739 & 2.5 & 100 \\
\hline 25 & 1838.41 & 0.82 & 3.971 & 3.865 & 3.766 & 3.782 & 10 & 100 \\
\hline 26 & 1840.35 & 0.81 & 3.948 & 3.843 & 3.744 & 3.759 & 2.5 & 101 \\
\hline 27 & 1843.35 & 0.83 & 3.917 & 3.843 & 3.739 & 3.773 & 12.5 & 100 \\
\hline 28 & 1846.27 & 0.96 & 3.950 & 3.879 & 3.747 & 3.781 & 12.5 & 94 \\
\hline 29 & 1848.13 & 0.76 & 3.916 & 3.845 & 3.745 & 3.745 & 10 & 93 \\
\hline 30 & 1850.35 & 0.94 & 3.928 & 3.854 & 3.751 & 3.751 & 7.5 & 99 \\
\hline 31 & 1852.09 & 0.63 & 3.905 & 3.834 & 3.701 & 3.714 & 7.5 & 99 \\
\hline 32 & 1853.56 & 0.64 & 3.881 & 3.846 & 3.744 & 3.744 & 5 & 95 \\
\hline 33 & 1856.35 & 0.85 & 3.938 & 3.865 & 3.729 & 3.739 & 5 & 94 \\
\hline 34 & 1859.09 & 1.1 & 3.920 & 3.862 & 3.753 & 3.770 & 7.5 & 103 \\
\hline 35 & 1861.26 & 0.92 & 3.933 & 3.827 & 3.728 & 3.749 & 0 & 100 \\
\hline 36 & 1864.22 & 0.92 & 3.954 & 3.869 & 3.748 & 3.769 & 0 & 101 \\
\hline 37 & 1866.27 & 1.4 & 3.944 & 3.874 & 3.775 & 3.774 & 0 & 100 \\
\hline 38 & 1868.27 & 0.67 & 3.931 & 3.865 & 3.761 & 3.771 & 7.5 & 99 \\
\hline 39 & 1870.76 & 0.73 & 3.939 & 3.845 & 3.740 & 3.749 & 5 & 99 \\
\hline 40 & 1872.35 & 1.3 & 3.960 & 3.856 & 3.727 & 3.769 & 7.5 & 94 \\
\hline 41 & 1875.26 & 0.97 & 3.930 & 3.857 & 3.753 & 3.769 & 12.5 & 99 \\
\hline 42 & 1875.66 & 0.85 & 3.956 & 3.860 & 3.771 & 3.769 & 5 & 99 \\
\hline 43 & 1877.08 & 0.85 & 3.946 & 3.874 & 3.773 & 3.774 & 7.5 & 96 \\
\hline 44 & 1878.54 & 1.5 & 3.960 & 3.853 & 3.785 & 3.785 & 7.5 & 101 \\
\hline 45 & 1880.85 & 0.86 & 3.952 & 3.879 & 3.744 & 3.744 & 7.5 & 103 \\
\hline 46 & 1882.43 & 1.6 & 3.988 & 3.874 & 3.767 & 3.785 & 10 & 103 \\
\hline 47 & 1886.08 & 1.3 & 3.966 & 3.847 & 3.773 & 3.792 & 7.5 & 100 \\
\hline 48 & 1888.29 & 0.78 & 3.917 & 3.848 & 3.750 & 3.759 & 12.5 & 99 \\
\hline 49 & 1889.57 & 0.86 & 3.912 & 3.843 & 3.777 & 3.774 & 5 & 95 \\
\hline 50 & 1892.61 & 1.3 & 3.953 & 3.881 & 3.781 & 3.819 & 20 & 104 \\
\hline 51 & 1893.55 & 1.5 & 3.983 & 3.877 & 3.777 & 3.787 & 5 & 101 \\
\hline 52 & 1894.37 & 1.4 & 3.977 & 3.866 & 3.779 & 3.779 & 12.5 & 100 \\
\hline 53 & 1897.37 & 2.0 & 3.977 & 3.852 & 3.768 & 3.799 & 7.5 & 91 \\
\hline 54 & 1899.37 & 0.79 & 3.975 & 3.865 & 3.746 & 3.779 & 10 & 99 \\
\hline 55 & 1901.37 & 1.1 & 3.941 & 3.853 & 3.753 & 3.777 & 10 & 99 \\
\hline 56 & 1904.37 & 1.0 & 3.958 & 3.885 & 3.748 & 3.779 & 12.5 & 99 \\
\hline 57 & 1906.39 & 1.2 & 3.902 & 3.848 & 3.796 & 3.796 & 5 & 103 \\
\hline 58 & 1908.37 & 1.3 & 3.968 & 3.860 & 3.758 & 3.759 & 5 & 93 \\
\hline 59 & 1910.37 & 0.99 & 3.919 & 3.846 & 3.743 & 3.754 & 7.5 & 98 \\
\hline 60 & 1913.29 & 1.4 & 3.957 & 3.885 & 3.749 & 3.764 & 7.5 & 99 \\
\hline 61 & 1915.37 & 1.8 & 3.992 & 3.901 & 3.812 & 3.809 & 5 & 96 \\
\hline 62 & 1917.38 & 1.1 & 3.902 & 3.865 & 3.726 & 3.729 & 0 & 96 \\
\hline
\end{tabular}


TABLE II. WAVE-VELOCITY SAMPLES FROM THE WISCONSIN-AGE DYE 3 ICE CORE

\begin{tabular}{|c|c|c|c|c|c|c|c|c|}
\hline $\begin{array}{c}\text { Sample } \\
\text { no. }\end{array}$ & $\begin{array}{l}\text { Sample } \\
\text { depth } \\
\text { m }\end{array}$ & $\begin{array}{l}\text { Grain- } \\
\text { size } \\
\text { mm }\end{array}$ & $\begin{array}{l}V_{\max 1} \\
\mathrm{~km} / \mathrm{s}\end{array}$ & $\mathrm{V}_{\max 2} \mathrm{km/s}$ & $\mathrm{V}_{\min } \mathrm{km/s}$ & $\begin{array}{l}\mathrm{V}(45) \\
\mathrm{km} / \mathrm{s}\end{array}$ & $\begin{array}{c}\text { Angle } \\
(\theta) \\
\text { degree }\end{array}$ & $\begin{array}{l}\text { Angle } \\
(\phi) \\
\text { degree }\end{array}$ \\
\hline 63 & 1920.37 & 1.3 & 3.952 & 3.879 & 3.744 & 3.761 & 10 & 100 \\
\hline 64 & 1923.29 & 1.6 & 3.931 & 3.858 & 3.755 & 3.777 & 5 & 99 \\
\hline 65 & 1925.89 & 1.7 & 3.935 & 3.828 & 3.761 & 3.759 & 5 & 93 \\
\hline 66 & 1927.37 & 1.5 & 3.934 & 3.860 & 3.790 & 3.790 & 5 & 100 \\
\hline 67 & 1929.44 & 1.5 & 3.930 & 3.858 & 3.790 & 3.794 & 5 & 101 \\
\hline 68 & 1931.34 & 0.87 & 3.897 & 3.860 & 3.755 & 3.771 & 10 & 98 \\
\hline 69 & 1933.34 & 1.2 & 3.936 & 3.847 & 3.746 & 3.764 & 5 & 96 \\
\hline 70 & 1936.84 & 1.3 & 3.941 & 3.853 & 3.753 & 3.783 & 15 & 104 \\
\hline 71 & 1937.34 & 1.5 & 3.885 & 3.849 & 3.746 & 3.762 & 10 & 90 \\
\hline 72 & 1940.28 & 1.7 & 3.950 & 3.873 & 3.765 & 3.782 & 10 & 100 \\
\hline 73 & 1943.23 & 1.7 & 3.908 & 3.872 & 3.771 & 3.804 & 15 & 96 \\
\hline 74 & 1943.31 & 1.4 & 3.863 & 3.827 & 3.758 & 3.769 & 12.5 & 91 \\
\hline 75 & 1944.31 & 1.6 & 3.970 & 3.860 & 3.791 & 3.789 & 7.5 & 99 \\
\hline 76 & 1947.31 & 1.6 & 3.978 & 3.870 & 3.769 & 3.769 & 5 & 98 \\
\hline 77 & 1950.57 & 1.1 & 3.979 & 3.871 & 3.770 & 3.769 & 2.5 & 100 \\
\hline 78 & 1952.31 & 0.81 & 3.919 & 3.846 & 3.743 & 3.743 & 5 & 96 \\
\hline 79 & 1955.33 & 0.85 & 3.943 & 3.868 & 3.763 & 3.764 & 7.5 & 96 \\
\hline 80 & 1957.31 & 1.3 & 3.972 & 3.879 & 3.775 & 3.775 & 0 & 101 \\
\hline 81 & 1959.31 & 0.77 & 3.923 & 3.853 & 3.720 & 3.769 & 10 & 98 \\
\hline 82 & 1962.31 & 1.1 & 3.919 & 3.866 & 3.765 & 3.783 & 15 & 94 \\
\hline 83 & 1964.26 & 0.89 & 3.955 & 3.845 & 3.792 & 3.824 & 22.5 & 90 \\
\hline 84 & 1966.46 & 0.88 & 3.921 & 3.850 & 3.749 & 3.749 & 5 & 95 \\
\hline 85 & 1968.26 & 1.4 & 3.961 & 3.856 & 3.789 & 3.824 & 17.5 & 109 \\
\hline 86 & 1971.26 & 2.0 & 3.992 & 3.882 & 3.747 & 3.779 & 7.5 & 104 \\
\hline 87 & 1973.26 & 1.9 & 3.944 & 3.873 & 3.790 & 3.806 & 10 & 103 \\
\hline 88 & 1975.26 & 1.9 & 3.997 & 3.891 & 3.789 & 3.804 & 12.5 & 103 \\
\hline 89 & 1977.26 & 2.3 & 3.983 & 3.877 & 3.777 & 3.777 & 7.5 & 101 \\
\hline 90 & 1979.26 & 1.7 & 3.963 & 3.869 & 3.763 & 3.782 & 10 & 103 \\
\hline 91 & 1982.26 & 1.5 & 3.945 & 3.876 & 3.746 & 3.778 & 10 & 99 \\
\hline 92 & 1985.26 & 2.2 & 3.957 & 3.849 & 3.780 & 3.779 & 2.5 & 99 \\
\hline 93 & 1988.26 & 2.4 & 3.963 & 3.854 & 3.786 & 3.786 & 2.5 & 100 \\
\hline 94 & 1991.26 & 1.7 & 3.988 & 3.882 & 3.783 & 3.799 & 10 & 103 \\
\hline 95 & 1993.26 & 1.6 & 3.982 & 3.874 & 3.790 & 3.789 & 5 & 100 \\
\hline 96 & 1995.18 & 2.9 & 3.948 & 3.877 & 3.809 & 3.834 & 12.5 & 108 \\
\hline 97 & 1996.57 & 1.9 & 3.978 & 3.869 & 3.767 & 3.767 & 5 & 99 \\
\hline 98 & 1999.18 & 2.3 & 3.955 & 3.882 & 3.778 & 3.804 & 5 & 99 \\
\hline 99 & 1999.26 & 1.6 & 3.956 & 3.868 & 3.784 & 3.817 & 20 & 105 \\
\hline 100 & 2002.26 & 2.6 & 4.000 & 3.860 & 3.761 & 3.768 & 2.5 & 106 \\
\hline 101 & 2004.61 & 2.2 & 3.974 & 3.866 & 3.765 & 3.773 & 5 & 100 \\
\hline 102 & 2006.05 & 2.2 & 3.979 & 3.874 & 3.743 & 3.766 & 2.5 & 111 \\
\hline 103 & 2008.05 & 2.0 & 3.937 & 3.865 & 3.763 & 3.780 & 7.5 & 100 \\
\hline 104 & 2010.05 & 2.0 & 3.992 & 3.863 & 3.793 & 3.794 & 0 & 105 \\
\hline 105 & 2013.05 & 1.7 & 4.000 & 3.854 & 3.786 & 3.803 & 7.5 & 104 \\
\hline 106 & 2015.07 & 1.2 & 3.959 & 3.853 & 3.785 & 3.784 & 5 & 103 \\
\hline 107 & 2018.07 & 0.74 & 3.952 & 3.879 & 3.775 & 3.775 & 7.5 & 100 \\
\hline 108 & 2020.07 & 0.74 & 3.955 & 3.848 & 3.749 & 3.772 & 12.5 & 101 \\
\hline 109 & 2023.07 & 0.76 & 3.966 & 3.857 & 3.771 & 3.805 & 12.5 & 99 \\
\hline 110 & 2025.95 & 0.82 & 3.959 & 3.853 & 3.720 & 3.779 & 15 & 109 \\
\hline 111 & 2027.03 & 0.68 & 3.962 & 3.852 & 3.782 & 3.782 & 10 & 100 \\
\hline 112 & 2029.44 & 0.74 & 3.958 & 3.849 & 3.763 & 3.779 & 2.5 & 99 \\
\hline 113 & 2032.02 & 0.60 & 3.962 & 3.853 & 3.751 & 3.779 & 15 & 103 \\
\hline 114 & 2034.00 & 0.45 & 3.911 & 3.839 & 3.771 & 3.789 & 7.5 & 101 \\
\hline
\end{tabular}

Superimposed on the crystal-size data in Figure 5 are the $\mathrm{SO}_{4}{ }^{2-}$ concentration levels for the same specimens (Langway and Goto-Azuma 1988, this volume). $\mathrm{SO}_{4}{ }^{2-}$ concentration levels are found at higher and of ten more variable concentrations than either $\mathrm{Cl}^{-}$or $\mathrm{NO}_{3}^{-}$. In the Wisconsin age $\mathrm{SO}_{4}{ }^{2-}$ ranges from about 20 to $210 \mathrm{ng} / \mathrm{g} ; \mathrm{Cl}^{-}$ ranges from about 20 to $100 \mathrm{ng} / \mathrm{g}$ and $\mathrm{NO}_{3}^{-}$ranges from about 25 to $80 \mathrm{ng} / \mathrm{g}$. In general the curves for $\mathrm{SO}_{4}{ }^{2-}$ and $\mathrm{Cl}^{-}$are coherent, increasing and decreasing in unison on a long-term basis. On the other hand, the $\mathrm{NO}_{3}{ }^{-}$concentration levels vary in low frequency with the other two species over the long-term. 


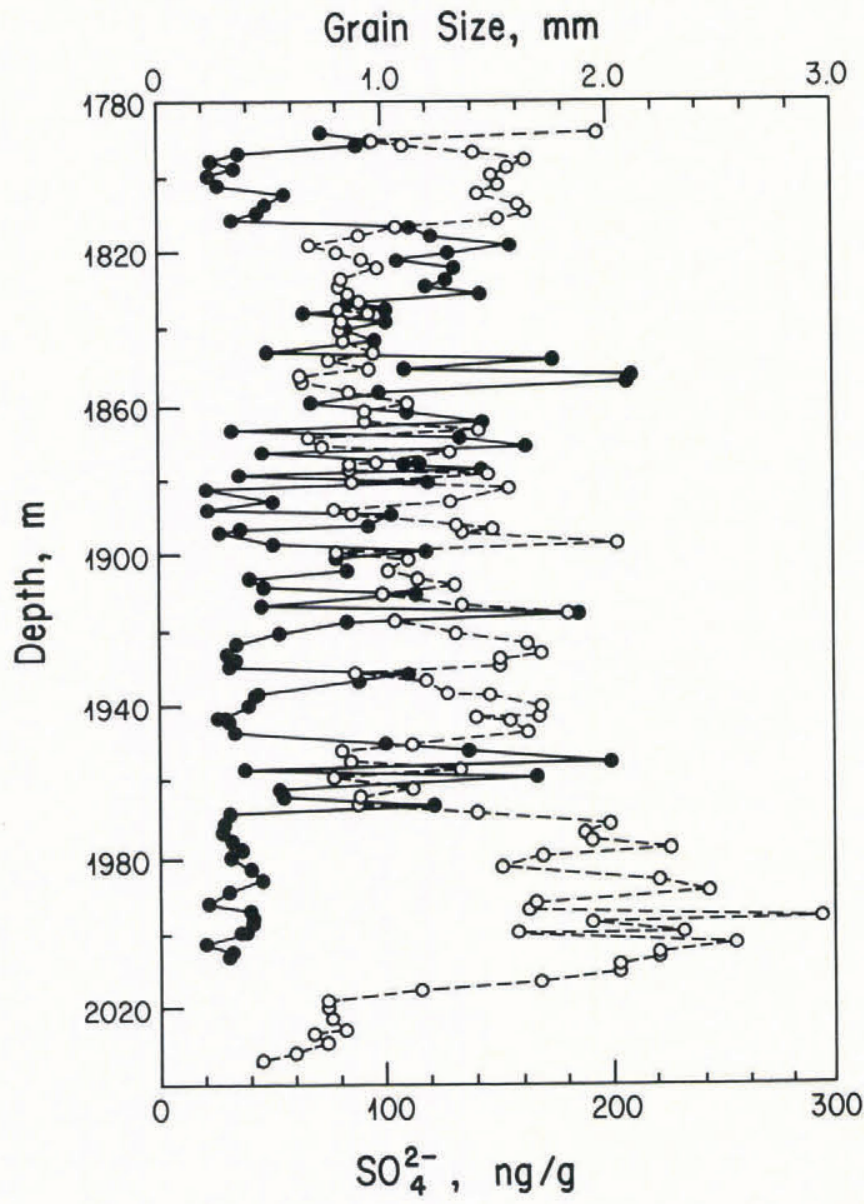

A comparison of the crystal-size curve with the $\mathrm{SO}_{4}{ }^{2-}$ concentration profile (Fig.5) clearly shows an inverse correlation. The smaller crystals are found at higher $\mathrm{SO}_{4}{ }^{2-}$ concentration levels and, conversely, the larger crystals are found at low $\mathrm{SO}_{4}{ }^{2-}$ concentration levels. A similar correlation is found with $\mathrm{Cl}^{-}$. The size of an ice crystal is influenced by the rate of grain-boundary migration and/or recrystallization. It is well known in metallurgy that average crystal size increases over time, to lower the free energy of the ice crystals by minimizing the total grain-boundary area. This process takes place in the form of grain-boundary migration. Chemical impurities at grain boundaries cause grain-boundary migration to be retarded, resulting in a relative reduction in crystal size. The process of recrystallization may also cause reductions in crystal size by the nucleation of more crystals in a unit mass of ice. The intragranular or intergranular locations of impurities may also serve as nucleation sites for recrystallization, by lowering the crystal-boundary energy of the nucleated crystals. Another cause for crystal-size reduction is the rearrangement of dislocations to form new crystal boundaries. These processes take place by plastic deformation, accompanied by dislocation multiplication processes which may be affected by the existence of impurities. Little is known about the exact roles of $\mathrm{SO}_{4}{ }^{2-}$, $\mathrm{Cl}^{-}$or other impurities in the above processes. Dust is another parameter which has an inverse correlation with crystal size (Hammer and others 1985). It is clear that a strong positive cross-correlation exists between $\mathrm{SO}_{4}{ }^{2-}, \mathrm{Cl}^{-}$ and dust and crystal size. However, more research is essential to explain the relative influences these species have on grain-size variation.

In summary, this investigation has shown by crystal-size and $c$-axis measurements that no changes have occurred in these parameters during the period of more than 5 years since the Dye 3 ice core was recovered. A new multi-directional ultrasonic wave-velocity measurement technique provides an accurate and relatively rapid method of obtaining mean $c$-axis orientation patterns from ice cores. Results of the 22 new thin-section analyses on the Wisconsin-age ice indicate that strong single-maximum fabric patterns exist at all levels measured. The results of the 114 ultrasonically measured specimens confirm the uniformly strong elastic anisotropy in Wisconsin-age ice, and in the bottom $29 \mathrm{~m}$ of silty ice, due to the strongly preferred, near-vertical, $c$-axis orientations. Crystal sizes range between 0.5 and $3.0 \mathrm{~mm}$. Smaller-size crystals are found at high impurity concentrations and, conversely, larger crystals are found at low impurity concentrations. These multiple-study results indicate that crystal size is influenced by impurity content but that impurity concentration levels have less of an effect on the formation of orientation patterns.

\section{ACKNOWLEDGEMENTS}

This work was supported by the U.S. National Science Foundation (DPP grant no. 8520911). The Department of Applied Physics, Hokkaido University, Japan, made possible the visit of N. Azuma to the State Univesity of New York at Buffalo for two months in 1984 to conduct the manual thin-section analyses. The chemical measurements were made by Carol Clemency and Dr K Goto-Azuma. angway and Goto-Azuma 1988 , this volu For these reasons $\mathrm{SO}_{4}{ }^{2-}$ was chosen as the most representative soluble impurity for examination in terms of the effects of impurities in the metamorphic processes governing changes in ice $c$-axes and crystal growth. The correlation between the $c$-axis fabric patterns and $\mathrm{SO}_{4}{ }^{2-}$ content was investigated in detail. The results show that higher $\mathrm{SO}_{4}{ }^{2-}$ content is always associated with higher $6 \mathrm{~V}$ (stronger $c$-axis concentration) and large $\phi$ or smaller $\theta$ values (less inclination of pole direction from the vertical core axis). On the other hand, wider variations are observed in $\delta \mathrm{V}, \phi$ and $\theta$ when the $\mathrm{SO}_{4}{ }^{2-}$ content is low. A similar relationship was observed when correlating the $\mathrm{Cl}^{-}$ concentration levels. These findings suggest that a high concentration of chemical impurities may help to develop and strengthen the vertical preference of $c$-axis orientation patterns in the Wisconsin-age ice. Since all of the Wisconsin-age ice samples have strong single-maximum fabric patterns (including the low impurity-content samples), impurities alone cannot be the only parameter which controls the $c$-axis orientations.

\section{REFERENCES}

Azuma N Unpublished Experimental studies on the development of texture and the flow behavior of ice in polar ice sheets. (PhD thesis, Hokkaido University, 1986)

Bennett H F 1972 Measurements of ultrasonic wave velocities in ice cores from Greenland and Antarctica. CRREL Research Report 237

Dansgaard W and 6 others 1982 A new Greenland deep ice core. Science 218(4579): 1273-1277

Dansgaard W, Clausen H B, Gundestrup N, Johnsen S J, Rygner C 1985 Dating and climatic interpretation of two deep Greenland ice cores. In Langway C C Jr, Oeschger H, Dansgaard W (eds) Greenland ice core: geophysics, geochemistry and the environment. Washington, DC, American Geophysical Union: 71-76 (Geophysical Monograph 33) 
Gundestrup N S, Johnsen S J 1985 A battery powered, instrumented deep ice core drill for liquid filled holes. In Langway C C Jr, Oeschger $\mathrm{H}$, Dansgaard W (eds) Greenland ice core: geophysics, geochemistry and the environment. Washington, DC, American Geophysical Union: 19-22 (Geophysical Monograph 33)

Hammer C U, Clausen H B, Dansgaard W, Neftel A, Kristinsdottir P, Johnson E 1985 Continuous impurity analysis along the Dye 3 deep core. In Langway C C Jr, Oeschger H, Dansgaard W (eds) Greenland ice core: geophysics, geochemistry and the environment. Washington, DC. American Geophysical Union: 90-94 (Geophysical Monograph 33)

Herron M M, Langway C C Jr 1985 Chloride, nitrate, and sulfate in the Dye 3 and Camp Century, Greenland ice cores. In Langway C C Jr, Oeschger $\mathrm{H}$, Dansgaard $\mathrm{W}$ (eds) Greenland ice core: geophysics, geochemistry and the environment. Washington, DC, American Geophysical Union: 77-84 (Geophysical Monograph 33)

Herron S L, Langway C C Jr, Brugger K A 1985 Ultrasonic velocities and crystalline anisotropy in the ice core from Dye 3, Greenland. In Langway C C Jr, Oeschger H, Dansgaard W (eds) Greenland ice core: geophysics, geochemistry and the environment. Washington, DC, American Geophysical Union: 23-31 (Geophysical Monograph 33)

Kohnen H, Bentley C R 1977 Ultrasonic measurements on ice cores from Ross Ice Shelf, Antarctica, drill hole. Antarctic Journal of the United States 12(4): 148-150

Kohnen H, Langway C C Jr 1977 Untersuchungen mit Ultraschall an Eisbohrkernen aus Zentralgrönland. Polarforschung 47(1/2): 1-10

Langway C C Jr 1958 Ice fabrics and the universal stage. US Army Snow, Ice and Permafrost Research Establishment. Technical Report 62

Langway C C Jr, Goto-Azuma K 1988 Temporal variations in the deep ice core chemistry record from Dye 3, Greenland. Annals of Glaciology 10: 209

Langway C C Jr, Oeschger H, Dansgaard W 1985 The Greenland Ice Sheet Program in prespective. In Langway C C $\mathrm{Jr}$, Oeschger $\mathrm{H}$, Dansgaard $\mathrm{W}$ (eds) Greenland ice core: geophysics, geochemistry and the environment. Washington, DC, American Geophysical Union: 1-8 (Geophysical Monograph 33)

Shoji H, Langway C C Jr 1982 Air hydrate inclusions in fresh ice core. Nature 298(5874): 548-550

Shoji H, Langway C C Jr 1983 Volume relaxation of air inclusions in a fresh ice core. Journal of Physical Chemistry 87(21): 4111-4114

Shoji H, Langway C C Jr 1985 The ice flow velocity profile for Dye-3, Greenland. Geophysical Research Letters 12(12): 797-800 